\title{
ZnO and MgO Decorated with Spherical Gold Nanoparticles
}

Fernando D. Cortes-Vega ${ }^{1}$, Nikte M. Gomez-Ortiz ${ }^{2}$, S. E. Borjas-Garcia ${ }^{2}$ and P. Martinez-Torres ${ }^{2}$

${ }^{1 .}$ Instituto de Investigaciones en Metalurgia y Materiales, Universidad Michoacana de San Nicolás de Hidalgo, Morelia, Michoacán, México.

2. Instituto de Física y Matemáticas, Universidad Michoacana de San Nicolás de Hidalgo, Morelia, Michoacán, México.

$\mathrm{ZnO}$ and $\mathrm{MgO}$ are attractive materials for its use in applications of catalysis, optics, chemical and electrochemical biosensors, optoelectronics, bioactivity and many others [1,2]. Gold nanoparticles are able to generate localized surface plasmon resonance. The addition of these nanoparticles to metal oxide materials like $\mathrm{ZnO}$ and $\mathrm{MgO}$ could improve their optical properties. It has been reported that the surface plasmon of $\mathrm{Au}$ nanoparticles enhanced $\mathrm{MgZnO}$ used as ultraviolet photodetector [3]. In this work we present the synthesis and process for decoration of these oxides with spherical gold nanostructures, as well as their characterization by means of SEM and XRD.

The $\mathrm{ZnO}$ and $\mathrm{MgO}$ were synthesized from Zinc and Magnesium nitrate hexahydrate $\left(\mathrm{Zn}\left(\mathrm{NO}_{3}\right) \cdot 6 \mathrm{H}_{2} \mathrm{O}\right.$ and $\left.\mathrm{Mg}\left(\mathrm{NO}_{3}\right) \cdot 6 \mathrm{H}_{2} \mathrm{O}\right)$, using $\mathrm{NaOH}$ as the precipitant agent. The solutions of $\left(\mathrm{Zn}\left(\mathrm{NO}_{3}\right) \cdot 6 \mathrm{H}_{2} \mathrm{O}\right.$ and $\left.\mathrm{Mg}\left(\mathrm{NO}_{3}\right) \cdot 6 \mathrm{H}_{2} \mathrm{O}\right)$ were prepared at $0.2 \mathrm{M}$, then the $\mathrm{NaOH}$ solution at $0.4 \mathrm{M}(100 \mathrm{ml})$ was dropped slowly at room temperature and constant stirring until the end of the reaction. The as-obtained precipitates (hydroxides) were washed several times with water and ethanol to ensure the elimination of residual nitrates. The products obtained after washing were dried at $50{ }^{\circ} \mathrm{C}$ for $24 \mathrm{~h}$ and then calcined at $500^{\circ} \mathrm{C}$ for $2 \mathrm{~h}$ to obtain $\mathrm{ZnO}$ and $\mathrm{MgO}$. In order to synthesize the $\mathrm{Au}$ nanoparticles, we followed the process reported in ref. [4], using gold (III) chloride trihydrate and trisodium citrate (TSC) as raw materials. Initially, $50 \mathrm{ml}$ of deionized water and $50 \mathrm{mg}$ of TSC were added into a flask and heated to boiling temperature with vigorous stirring. Then, $150 \mathrm{ml}$ of $\mathrm{HAuCl}_{4} 0.25 \mathrm{M}$ were added keeping temperature and stirring up to the solution turns into a ruby-red color, which indicates the formation of the $\mathrm{Au}$ nanoparticles. The oxide powders were mixed with $120 \mathrm{ml}$ of colloidal Au nanoparticles and stirred for $1 \mathrm{~h}$ followed by a drying process at $100{ }^{\circ} \mathrm{C}$ for $24 \mathrm{~h}$. These powders were placed into a stainless steel die to obtain green pellets of $1 \mathrm{~cm}$ of diameter and $1.5 \mathrm{~mm}$ of thickness. The green pellets were calcined at $1000{ }^{\circ} \mathrm{C}$ for $2 \mathrm{~h}$ using a conventional furnace. The crystal structure of both $\mathrm{ZnO} \backslash \mathrm{Au}$ and $\mathrm{MgO} \backslash \mathrm{Au}$ pellets was identified using $\mathrm{X}$ ray diffraction.

In Figure $1 \mathrm{a}$ and $1 \mathrm{~b}$ are showed the well crystallized phases from both oxides, which are in good agreement with the pattern references JCPDS 00-036-1451 and 00-087-0653 for ZnO (zincite) and MgO (periclase), respectively. The presence of gold is evident in both samples by the identification of the reflections (111), (200), (220) and (311) according to the standard reference JCPDS 04-0784 [5]. The SEM images displayed in Figure $2 \mathrm{a}$ and $\mathrm{b}$ show plates and spheres morphology for $\mathrm{ZnO}$ and $\mathrm{MgO}$, respectively. Au nanoparticles were spheres with homogeneous distribution for both cases, $\mathrm{ZnO}$ and $\mathrm{MgO}$. Surprisingly, the size of the Au nanoparticles increased considerably from $20 \mathrm{~nm}$ (asynthesized nanoparticles) to $276 \pm 53 \mathrm{~nm}$ for the $\mathrm{ZnO}$ decorated with $\mathrm{Au}$ nanoparticles and, similarly, the $\mathrm{Au}$ nanoparticles deposited on $\mathrm{MgO}$ showed an increase in size from $20 \mathrm{~nm}$ to $181 \pm 55 \mathrm{~nm}$. However, other works have reported the sustainability of size of the Au nanoparticles at temperatures up to $1000{ }^{\circ} \mathrm{C}$ [5]. This growth of the Au nanoparticles may be associated to the agglomeration and subsequent sintering of them. On the other hand, the $\mathrm{ZnO}$ and $\mathrm{MgO}$ particles exhibit different morphology to that observed for conventional synthesis of the materials without Au nanoparticles [6]. 
References:

[1] E. Wongrat et al, Sensors Actuators A Phys. 251 (2016), p. 188.

[2] I. Unlu et al, Langmuir 31 (2015), p. 8718.

[3] Z.X. Guo et al, Opt. Commun. 399 (2017), p. 68.

[4] C. Li et al, Nanoscale Res. Lett. 6 (2011), p. 440.

[5] F. D. Cortes-Vega et al, J. Mater. Chem. C 5 (2017), p.4959.

[6] This work was partially funded by Consejo de la Investigación Científica UMSNH, research project 2018 and Fortalecimiento de Cuerpos Académicos Convocatoria 2017.
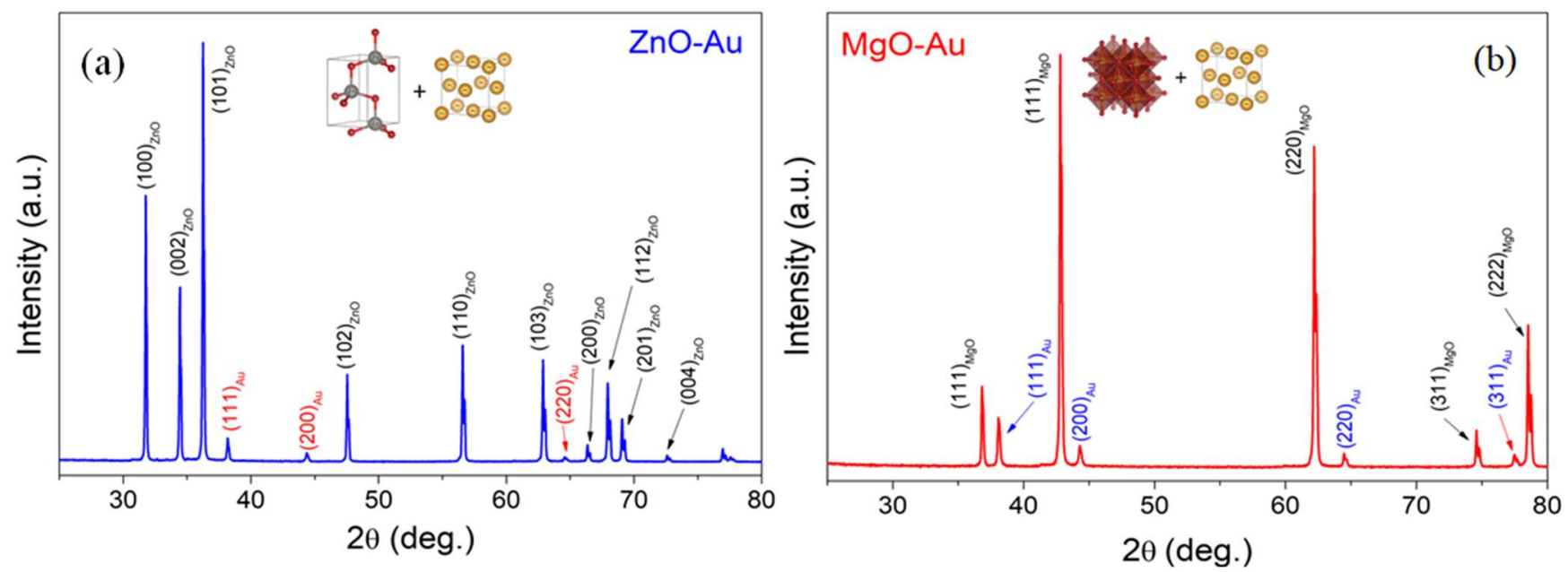

Figure 1. XRD analyses of $\mathrm{ZnO}$ and $\mathrm{MgO}$ decorated with gold nanoparticles after heat treatment at $500{ }^{\circ} \mathrm{C}$.
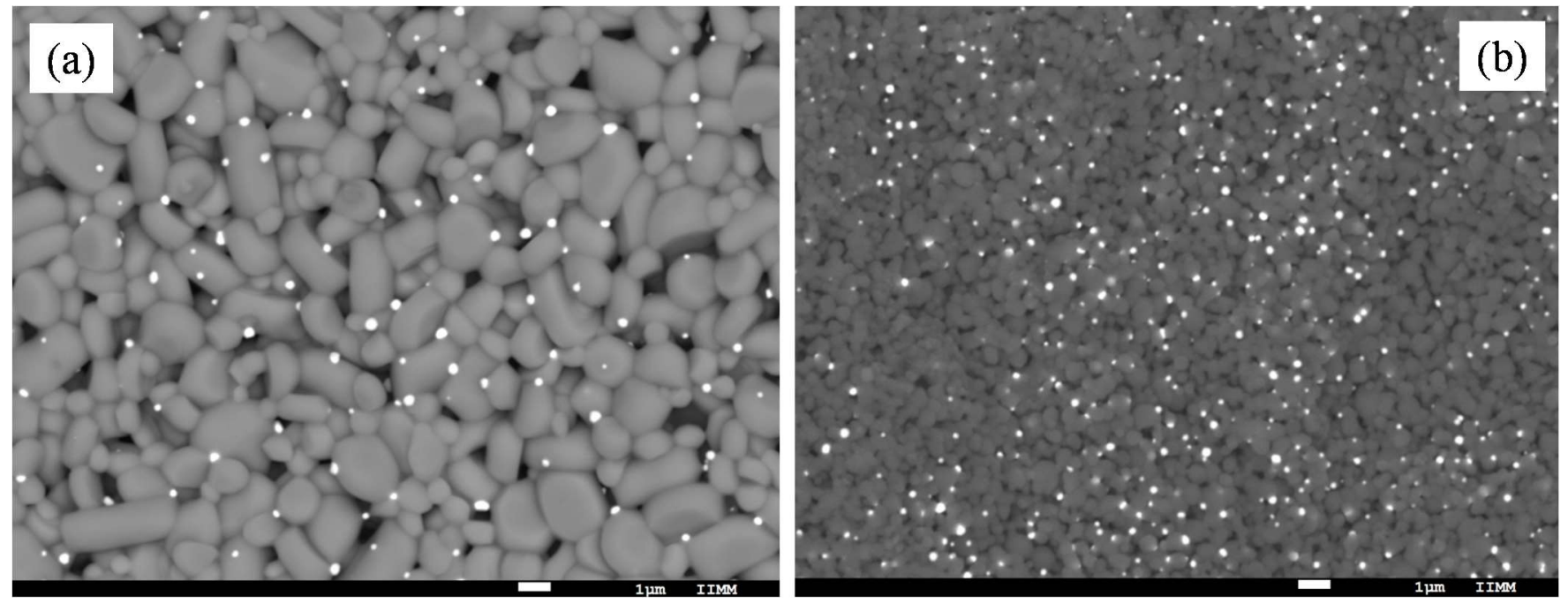

Figure 2. SEM images of $\mathrm{ZnO}$ and $\mathrm{MgO}$ decorated with spherical gold nanoparticles. 